\title{
Carbohydrate Fermentation in the Human Colon and Its Relation to Acetate Concentrations in Venous Blood
}

\author{
E. W. Pomare, W. J. Branch, and J. H. Cummings \\ Medical Research Council Dunn Clinical Nutrition Center, Old Addenbrooke's Hospital, Cambridge, CB2 1QE, England
}

\begin{abstract}
There is now substantial evidence that some dietary polysaccharides, notably dietary fiber, escape absorption in the small bowel and are then broken down in the large intestine of man. The main end products of this colonic digestive process, which is anerobic, are short chain fatty acids (SCFA), and acetic, propionic, and butyric acids. Although these acids are known to be absorbed from the colon, their subsequent fate and significance is unknown. We have measured venous blood SCFA levels in healthy subjects after a 16-h fast, and then following oral doses of either $50 \mathrm{mmol}$ SCFA, 5, 10, or $20 \mathrm{~g}$ doses of the fermentable carbohydrate lactulose, or $20 \mathrm{~g}$ of pectin. Fasting venous blood acetate was $53.8 \pm 4.4 \mu \mathrm{mol} /$ liter (SEM) $(n=14)$. Fasting arterial blood acetate, taken simultaneously with venous blood in six subjects, was higher; 125.6 $\pm 13.5 \mu \mathrm{mol} / \mathrm{liter}$ (arterial) vs. 61.1 $\pm 6.9 \mu \mathrm{mol} / \mathrm{liter}$ (venous). Significant levels of propionate or butyrate were not detected in any blood samples. Following an oral dose of $\mathbf{5 0}$ mmol mixed SCFA, venous blood acetate reached a peak of 194.1 $\pm 57.9 \mu \mathrm{mol} / \mathrm{liter}$ at $45 \mathrm{~min}$ and returned to fasting levels at $2 \mathrm{~h}$. Blood acetate also rose in response to lactulose, peak levels occurring 2-4 h after the dose: $5 \mathrm{~g}, 98.6 \pm 23.1 \mu \mathrm{mol} /$ liter; $10 \mathrm{~g}, 127.3 \pm 18.2 \mu \mathrm{mol} / \mathrm{liter}$; and $20 \mathrm{~g}, 181.3 \pm 23.9 \mu \mathrm{mol} /$ liter. Pectin fermentation was much slower, with blood acetate levels starting to rise after $6 \mathrm{~h}$ and remaining elevated at about twice fasting levels for the subsequent $18 \mathrm{~h}$. However, areas under the blood acetate curves were closely related $(r=0.97$; $n=5$ ), whatever the source of acetate. These studies show that the large intestine makes an important contribution to blood acetate levels in man and that fermentation may influence metabolic processes well beyond the wall of this organ.
\end{abstract}

\section{Introduction}

Carbohydrate breakdown by the anerobic flora of the gut is an important component of digestive physiology and metabolism in ruminants $(1,2)$ and is known as fermentation. In monogastric species, such as the horse (3), pig (4), guinea pig $(5,6)$ and rat $(7)$, fermentation occurs principally in the large intestine and, although quantitatively less than in the rumen, is nevertheless a significant contribution to the nutrition of these mammals (8-10). Fermentation also occurs in the large

Address correspondence to Dr. Pomare. Dr. Pomare's present address is Department of Medicine, Wellington Clinical School of Medicine, University of Otago, Wellington Hospital, Wellington, New Zealand.

Received for publication 6 July 1984 and in revised form 26 November 1984.

J. Clin. Invest.

(c) The American Society for Clinical Investigation, Inc.

0021-9738/85/05/1448/07 \$1.00

Volume 75, May 1985, 1448-1454 intestine of man (11) but its place, both in the normal function of the bowel and in metabolic events outside the colon, remains largely unknown.

The main end products of fermentation are short chain fatty acids (SCFA), ${ }^{1}$ acetic, propionic and butyric acid, which are the predominant anions in human feces (12). The gases methane, hydrogen, and carbon dioxide are also produced. Hydrogen and methane are not formed by human tissues and their excretion both in breath and per rectum has been used to monitor colonic carbohydrate metabolism in man (13-15). Fermentation is also the way in which the microflora of the large intestine obtain energy for maintenance of cellular function and growth $(16,17)$.

SCFA are the major product of fermentation and potentially the most important to the host. They are absorbed rapidly from the colonic lumen $(18,19)$ but their fate beyond this has been little studied in man. In the ruminant animal, these fatty acids make a major contribution to energy metabolism (1). Butyrate and propionate are largely cleared by the colonic mucosa or liver while acetate passes into the peripheral circulation $(20,21)$. In man, butyrate is metabolized by the colonic epithelial cells (22), but the fate of colonic acetate and propionate is not known. To investigate this we have measured SCFA in peripheral venous blood after either direct absorption from the gut or during fermentation of the disaccharide lactulose or the polysaccharide pectin.

\section{Methods}

\section{Subjects}

14 healthy subjects, all of whom were university students or staff ( 2 female, 12 male), average age 24.5 yr (range, 19-41) took part in the studies.

\section{Protocols}

From six subjects, single $10-\mathrm{ml}$ samples of venous and arterial blood were taken from the forearm after an overnight fast. The other eight subjects participated, in groups of five, in a series of three experiments all of which were carried out in the metabolic suite of the Dunn Clinical Nutrition Center. Subjects lived at the Center and all diets were supplied from the metabolic diet kitchen. They were encouraged to lead as normal a life as possible except during the actual hours of the tests. During the day before a study, subjects were asked to avoid foods containing dietary fiber. At 7 p.m. that evening, a polysaccharidefree meal was eaten consisting of prawns, $50 \mathrm{~g}$; mayonnaise (made from olive oil, egg yolk, and salt), $50 \mathrm{~g}$; chicken, $50 \mathrm{~g} ; 2$ eggs, $100 \mathrm{~g}$; butter, $18 \mathrm{~g}$; meringue, $41 \mathrm{~g}$; double cream, $53 \mathrm{~g}$; cheddar cheese, 44 $\mathrm{g}$; and coca cola, $330 \mathrm{ml}$. (Nutrient composition: energy, $6.1 \mathrm{MJ}$; protein, $52 \mathrm{~g}$; fat, $108 \mathrm{~g}$; carbohydrate [no starch or fiber], $75 \mathrm{~g}$ ). The subjects then fasted until 8 a.m. the following day when the studies commenced.

In the initial experiment, a $400 \mathrm{ml}$ drink of Perrier water was given

1. Abbreviations used in this paper: GC, gas chromatography; SCFA, short chain fatty acids. 
at the start $(08.00 \mathrm{~h})$ either on its own (control) or containing $30 \mathrm{mmo}$ acetate, $10 \mathrm{mmol}$ propionate, and $10 \mathrm{mmol}$ butyrate as the sodium salts adjusted to pH 7.0 with $1 \mathrm{M} \mathrm{NaOH}$. The order in which the drinks were taken was randomized. Venous blood samples were obtained at 15-min intervals for $2 \mathrm{~h}$ and then every half-hour for another $2 \mathrm{~h}$. Breath hydrogen was collected every $10 \mathrm{~min}$ and urine at the start and end of the study. The subjects rested in a comfortable chair throughout.

In the next study, five subjects followed a similar dietary protocol on the first day and then on the second day at 8 a.m. took, in random order, either 5,10 , or $20 \mathrm{~g}$ of lactulose as a syrup (Duphalac; Duphar Ltd., Southampton, England; containing $3.35 \mathrm{~g}$ lactulose, $0.3 \mathrm{~g}$ lactose, and $0.5 \mathrm{~g}$ galactose $/ 5 \mathrm{ml})$. Venous blood was sampled every half-hour and breath every 10 min until such time as breath hydrogen excretion had returned substantially to basal levels, usually at least $6 \mathrm{~h}$. Urine was collected at 0,4 , and $6 \mathrm{~h}$. Subjects who had not already done a control study with water alone did so.

Finally, five subjects were studied for $24 \mathrm{~h}$ after a dose of $20 \mathrm{~g}$ pectin. The day before the study the subjects followed the same dietary protocol as before, but on the day of the study at $08.00 \mathrm{~h}$ after collection of fasting blood, breath, and urine, a breakfast was eaten consisting of 2 eggs $(100 \mathrm{~g})$, lean bacon $(25 \mathrm{~g})$, jelly ( $44 \mathrm{~g}$ jelly powder) with or without pectin $(20 \mathrm{~g})$, double cream $(50 \mathrm{~g})$, and tea or coffee. During the rest of the day, meals were eaten at $4-h$ intervals and a drink was given two-hourly. The menu consisted of: lunch-lamb (50 $\mathrm{g})$, cheese $(30 \mathrm{~g})$, chicken $(50 \mathrm{~g})$, lemonade $(330 \mathrm{ml})$; dinner-pork $(100 \mathrm{~g})$, cream caramel (made from one egg [50 g], egg white [50 g], double cream [12 g], sugar [20 g]) with double cream $(30 \mathrm{~g})$, coca cola $(330 \mathrm{ml})$; evening snack-cheese $(40 \mathrm{~g})$, salmon $(30 \mathrm{~g})$, coca cola (330 $\mathrm{ml}$ ). (Total nutrient composition: energy, $8.6 \mathrm{MJ}$; protein, $129 \mathrm{~g}$; fat, $112 \mathrm{~g}$; carbohydrate, $138 \mathrm{~g}$ [no starch or fiber]). Blood was taken hourly during the day until midnight and every $2 \mathrm{~h}$ through the night. Breath was sampled every half hour until midnight and again every 2 h during the night. Urine was collected every $6 \mathrm{~h}$. Subjects rested quietly in their rooms throughout the whole $24-\mathrm{h}$ period.

All venous blood was obtained from the forearm, without compression, using an indwelling $20 \mathrm{~g}$ intravenous catheter (Jelco Ltd., Tampa, FL), kept open by flushing on each occasion with about $1 \mathrm{ml}$ of a solution of dilute heparin (100 units/ml). Blood was collected into tubes containing lithium-heparin anticoagulant, centrifuged immediately (1000 $\mathrm{g}$ for $10 \mathrm{~min}$ ), and then plasma was taken straight for SCFA analysis. End-expiratory breath was collected in a sampler which traps expired air in a collapsible polythene tube, similar to a party blower (H. S. Wiggins, unpublished data).

The studies were approved by the Ethical Committee of the MRC Dunn Nutrition Unit.

\section{Chemical methods}

All chemicals were either Aristar (BDH Chemicals Ltd., Poole, England) or the highest available purity. Chemicals were checked for acetate contamination before use by gas chromatography (GC) and those containing $>2 \mu \mathrm{mol} /$ liter were rejected.

Breath analysis. Methane was measured by GC using a Pye 104 gas chromatograph (Pye Instruments, Cambridge, England) fitted with a $2 \mathrm{ml}$ gas sampling loop and a flame ionization detector. Methane was separated on a $2 \mathrm{~m} \times 4 \mathrm{~mm}$ glass column packed with Poropak$\mathrm{Q}$ (Alltech Associates, Carnforth, England) at $50^{\circ} \mathrm{C}$ using nitrogen as carrier gas. The instrument was calibrated with a $50 \mathrm{ppm}$ standard gas (British Oxygen Co. Wolverhampton, England).

Hydrogen was measured with a selective electrochemical cell (GMI Exhaled Hydrogen Monitor, GMI Medical Ltd., Renfrew, Scotland), calibrated with a $96 \mathrm{ppm}$ standard gas. All breath samples were taken in duplicate and simultaneous samples of room air were used on each occasion as a control.

SCFA in blood. Plasma SCFA were determined in duplicate by GC following vacuum transfer $(23,24)$. After the plasma had been obtained, it was kept at $4^{\circ} \mathrm{C}$ until the start of the vacuum transfer procedure which was usually within $2-4 \mathrm{~h}$ of collection. Vacuum transfer was accomplished using a round-bottomed flask of $\sim 50 \mathrm{ml}$ capacity (5 cm external diameter, Quickfit $14 / 23$ ground glass joint) connected to a $10-\mathrm{ml}$ conical tube $(12 \times 1.5 \mathrm{~cm}$, Quickfit $14 / 23)$ by a 10-cm, U-shaped connecting piece which was fitted with a Quickfit glass tap (STO 1-2) (Camlab, Cambridge, England). The glass joints and taps were lubricated with a hydrocarbon-based grease.

To $1 \mathrm{ml}$ of plasma in the flask was added $1 \mathrm{ml}$ of $0.36 \mathrm{M}$ perchloric acid and $80 \mathrm{nmol}$ propionic acid as internal standard. The acidified mixture was shell frozen using liquid nitrogen. $0.25 \mathrm{ml}$ of $1 \mathrm{M}$ sodium hydroxide solution was simultaneously frozen in the conical tube. Immediately after freezing, the flask and conical tube were connected to the U-tube and then evacuated to $<0.1 \mathrm{mbar}$ with a double-stage vacuum pump. Evacuation was complete within $60 \mathrm{~s}$ in satisfactory assemblies. After evacuation, the conical tube was immersed in liquid nitrogen contained in a Dewar vessel $(22 \times 20 \mathrm{~cm}$, internal dimensions $)$ so that the lower $1-2 \mathrm{~cm}$ of it was covered. The flask remained at room temperature on the outside of the vessel, thus creating a temperature gradient for the transfer of water and volatile materials from flask to tube. A series of studies to check the recovery of SCFA from plasma were undertaken. ${ }^{14} \mathrm{C}$-labeled acetate, propionate, and butyrate (Radiochemical Center, Amersham, England) were added to fasting plasma and the procedure stopped at intervals for up to $2 \mathrm{~h}$. Fig. 1 shows that recoveries were maximal after $1 \mathrm{~h}$, although in practice the freeze-transfer procedure was allowed to continue for about $2 \mathrm{~h}$. At $2 \mathrm{~h}$, mean ( \pm SEM) recoveries were acetate, $97.3 \pm 0.8 \%$; propionate, $83.6 \pm 0.8 \%$; and butyrate, $79.6 \pm 0.8 \%$. Recoveries from urine were in the range $92-100 \%$. After transfer, the vacuum was released and the assembly removed from the Dewar vessel. Any condensate that had frozen around the neck of the conical tube was allowed to thaw. The contents were then mixed and refrozen before freeze-drying over a phosphorus pentoxide mixture using a $\mathrm{CO}_{2}$ methanol cold trap. Losses of ${ }^{14} \mathrm{C}$-labeled SCFA were $<5 \%$ during freeze-drying. The dried samples were taken up in $100 \mu \mathrm{l}$ of $3.33 \mathrm{M}$ phosphoric acid and $1 \mu \mathrm{l}$ was injected onto the column. Acetate standards were prepared from a stock solution $(2.5 \mathrm{mmol} / \mathrm{liter})$ and $25,62.5,125$, and $250 \mathrm{nmol}$ were added to $1 \mathrm{ml}$ of the subject's fasting plasma to prepare a standard curve.

Chromatography. A Pye 304 gas chromatograph (Pye Instruments) with a flame ionization detector was fitted with a $1.5 \mathrm{~m} \times 2 \mathrm{~mm}$ internal diameter glass column packed with phosphoric acid-treated Tenax 60-80 mesh (a porous polymer based on 2,6-diphenyl-p-phenylene oxide). The columns were conditioned at $150^{\circ} \mathrm{C}$ for several days before use. The column temperature was $125^{\circ} \mathrm{C}$, the injector and detector temperature was $200^{\circ} \mathrm{C}$, and argon carrier gas flow was $30 \mathrm{ml} / \mathrm{min}$. All gases were purified by passing through a molecular sieve and the

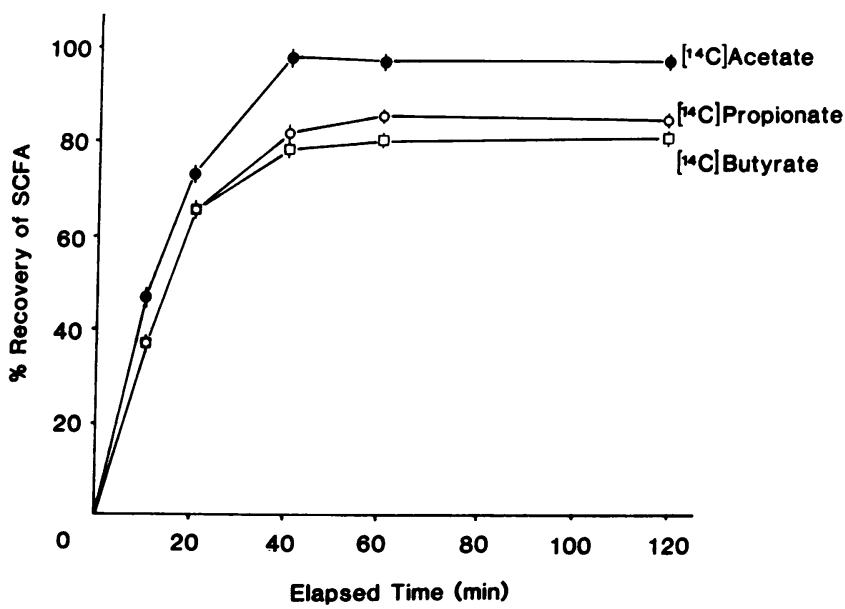

Figure 1. Percent recovery of $\left[{ }^{14} \mathrm{C}\right]$ acetate, propionate, and butyrate from plasma at various stages during freeze-transfer. Mean \pm 1 SEM. $n$ $=4$. 
hydrogen for the detector was additionally purified by passing through a combined molecular sieve cleaning column containing Chromopak.

The coefficient of variation for acetate measurements in 10 samples from the same fasting plasma was $4.5 \%$ (average value, $18.9 \mu \mathrm{mol} /$ liter). Plasma samples without internal standard were run as blanks in each experiment and were chosen to correspond to those with the lowest and highest acetate concentrations. This was in order to check on the appearance of propionate or butyrate during the study. Concentrations were $<2 \mu \mathrm{mol} /$ liter in most samples.

Statistics. SCFA values were computed relative to the internal standard by the peak-height ratio method and all results are given as means \pm 1 SEM. Statistical comparisons are with the Student's $t$ test. Areas under the curve were calculated from the equation:

Area $=\sum_{\mathfrak{t}}^{\mathfrak{n}}\left[\frac{\left(\mathrm{X}^{0}+\mathrm{X}^{1}\right)}{2}-\mathrm{F}\right] \times T$

where $\mathrm{X}$ is the plasma acetate concentration (micrometer/liter) at time 0 to time $n, T$ is the time interval in minutes, and $\mathrm{F}$ is the average fasting blood acetate from the control study for that subject.

\section{Results}

Fasting. Fasting blood acetate was $53.8 \pm 4.4 \mu \mathrm{mol} /$ liter (range, 28.1-93.3) in the 14 subjects. In six subjects whose fasting values were measured repeatedly (between three and eight times) during the 6 mo of the study, the coefficient of variation was $34.9 \pm 5.2 \%$. No significant $(<2.0 \mu \mathrm{mol} / \mathrm{liter})$ amounts of propionate, butyrate, or isobutyrate were detected in fasting blood. The subjects fasted for $12 \mathrm{~h}$ before each study but, in addition, plant polysaccharides and other potentially fermentable carbohydrates such as starch were excluded from their diet for the meal before the start of the fast. The effective period without known fermentable material by mouth was therefore at least $16 \mathrm{~h}$. Prolonging this "polysaccharide-free" period to $36 \mathrm{~h}$ did not lead to significantly different fasting blood acetate levels $(55.5 \pm 11.0 \mu \mathrm{mol} / \mathrm{liter}$ after $36 \mathrm{~h}, n=5)$. Fasting arterial blood acetates were significantly higher at $125.6 \pm 13.4 \mu \mathrm{mol} /$ liter than venous blood in the same subjects taken concurrently at $61.1 \pm 6.9 \mu \mathrm{mol} / \mathrm{liter}(t=4.884, P$ $<0.005, n=6)$. No propionate or butyrate ( $<2 \mu \mathrm{mol} / \mathrm{liter})$ was detected in arterial blood.

Fasting breath hydrogen was $13.6 \pm 2.2 \mathrm{ppm}$ and was not significantly correlated with blood acetate levels $(r=0.32)$. Two of the seven subjects who undertook the feeding studies had detectable levels of methane in breath (19 and $46 \mathrm{ppm}$ above room air in the fasting state).

SCFA by mouth. Fig. 2 shows the changes in blood acetate levels during a 4-h period following a drink of water containing the mixture of $30 \mathrm{mmol}$ acetate, $10 \mathrm{mmol}$ propionate, and 10 mmol butyrate or the control. Fasting acetate levels $(42.4 \pm 5.5$ $\mu \mathrm{mol} /$ liter) had doubled $15 \mathrm{~min}$ after the test dose, reached a peak of $194.1 \pm 57.9 \mu \mathrm{mol} / \mathrm{liter}$ at $45 \mathrm{~min}$, and were back to basal levels within $2 \mathrm{~h}$. No significant rise in propionate or butyrate was observed in any subject. Breath hydrogen was unchanged during these studies.

Lactulose. Next, a study was undertaken using lactulose to define the relationship between blood acetate and carbohydrate fermentation in the colon. Fig. 3 shows blood acetate levels over the first $6 \mathrm{~h}$ after the test doses. Lactulose always led to a rise in acetate but there was a variable delay between ingesting the dose and the onset of the rise in blood acetate. With the $5 \mathrm{~g}$ dose, this varied from 90-300 $\mathrm{min}$. The delay became less as the dose increased: $5 \mathrm{~g}$ dose, $171 \pm 41 \mathrm{~min} ; 10$

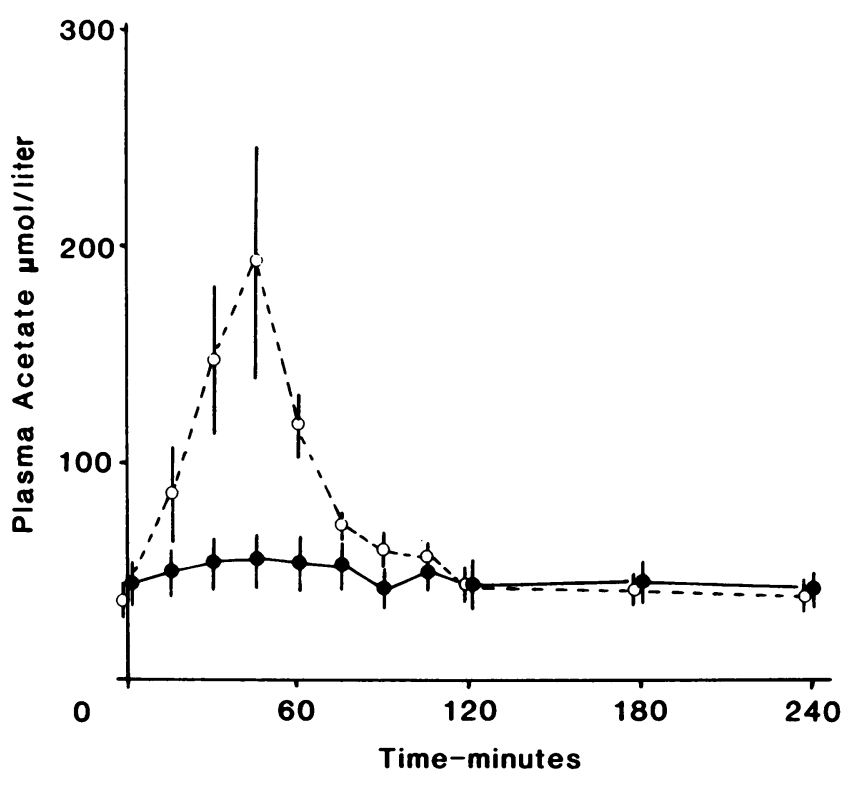

Figure 2. Plasma acetate in five subjects after drinking $400 \mathrm{ml}$ Perrier water (- - -) or the same with the addition of $30 \mathrm{mmol}$ acetate, 10 mmol propionate, and $10 \mathrm{mmol}$ butyrate (- - ). Mean \pm 1 SEM.

$\mathrm{g}$ dose, $94 \pm 19 \mathrm{~min}$; and $20 \mathrm{~g}$ dose, $78 \pm 22 \mathrm{~min}$. Similar delays were seen in the onset of the rise in breath hydrogen. Peak acetate concentrations increased progressively with the dose of lactulose from $98.6 \pm 23.1 \mu \mathrm{mol} / \mathrm{liter}(5 \mathrm{~g})$ to $127.3 \pm 18.2(10$ g) and $181.3 \pm 23.9 \mu \mathrm{mol} / \mathrm{liter}(20 \mathrm{~g})$. The area under the acetate curve was closely related to the dose of lactulose (Fig. 4). Fermentation continued for several hours in each subject, blood acetate returning finally to near fasting levels only 7-8 $h$ after the test dose was taken $(427 \pm 14 \mathrm{~min}$ [5 g], $438 \pm 29$ $\min [10 \mathrm{~g}$ ], and $446 \pm 42 \mathrm{~min}[20 \mathrm{~g}]$ ).

Breath hydrogen excretion, which was monitored primarily as a guide to the start and finish of the fermentative process in the colon, showed similar qualitative changes to those in blood acetate. The delay in the onset of the rise in breath hydrogen diminished as the dose of lactulose increased: $174 \pm 38$ $\min [5 \mathrm{~g}$ ], 84 $\pm 15 \mathrm{~min}[10 \mathrm{~g}$ ], and $68 \pm 19 \mathrm{~min}[20 \mathrm{~g}]$. Peak hydrogen levels increased with increasing dose of lactulose: $42 \pm 8 \mathrm{ppm}(5 \mathrm{~g}), 62 \pm 19 \mathrm{ppm}(10 \mathrm{~g})$, and $129 \pm 27 \mathrm{ppm}(20 \mathrm{~g})$.

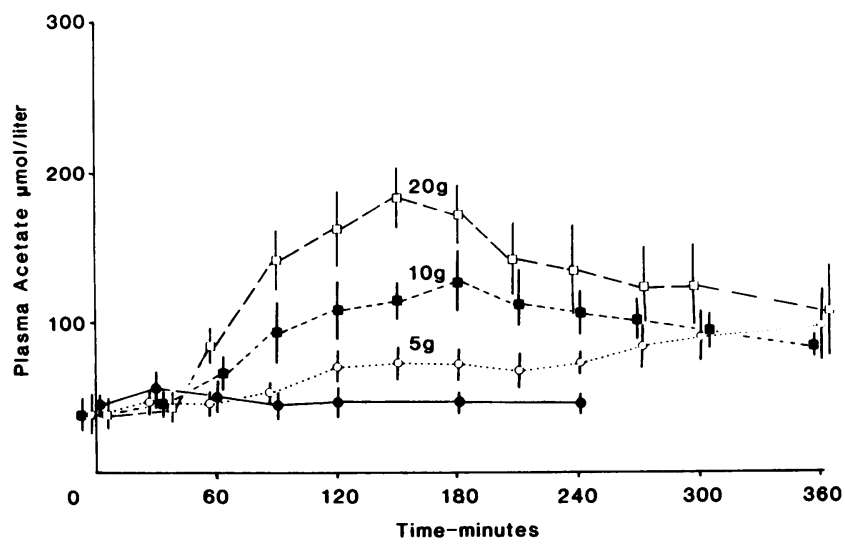

Figure 3. Plasma acetate in five subjects after drinking $400 \mathrm{ml}$ Perrier water (- - ) or the same with the addition of either $5 \mathrm{~g}(-\mathrm{O}-)$, $10 \mathrm{~g}(--)$, or $20 \mathrm{~g}(-\square-)$ of lactulose. Mean \pm 1 SEM. 


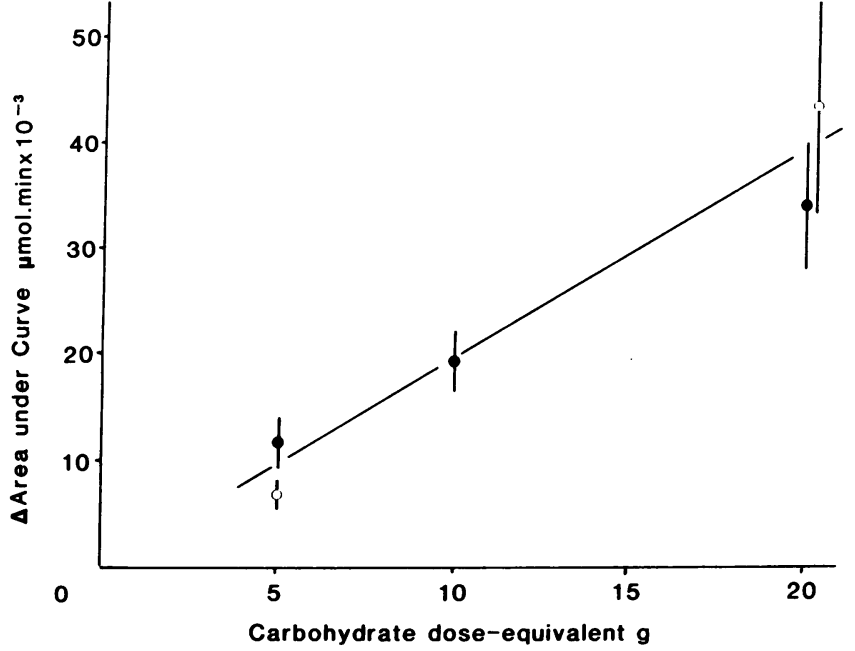

Figure 4. Changes in area under the blood acetate curve (test, average fasting value) in groups of five subjects after either 5,10 , or $20 \mathrm{~g}$ of lactulose, $\bullet ; 20 \mathrm{~g}$ pectin, $O$; or $50 \mathrm{mmol}$ SCFA, $O$; calculated as being equivalent to the fermentation of $5 \mathrm{~g}$ of carbohydrate (see reference 60). $r=0.97$, mean \pm 1 SEM.

Pectin. To observe fermentation from a polysaccharide present naturally in foods and to compare the response with that obtained with lactulose, studies were undertaken with pectin. Initially subjects were followed for $6 \mathrm{~h}$ after the test dose but this failed to record any change in blood acetate or breath hydrogen. This position was not altered by giving pectin with a polysaccharide-free meal. However, when subjects were observed for $12 \mathrm{~h}$, a rise in blood acetate was seen although peak levels were not achieved. Therefore, it was decided to study subjects for $24 \mathrm{~h}$ after the test dose and to include regular polysaccharide-free meals throughout the period. A control study with similar meals but without the pectin was included.

Fig. $5 \mathrm{~A}$ shows that blood acetate levels rose significantly after the pectin dose although they did not do so until $6 \mathrm{~h}$ and showed a broad peak for 8-14 h subsequently. Blood levels were still significantly above control values at $24 \mathrm{~h}$. Acetate was $\sim 50 \mu \mathrm{mol} /$ liter throughout the 24 -h control period although it showed some cyclical changes. Peak blood levels after pectin were $95.8 \pm 11.7 \mu \mathrm{mol} / \mathrm{liter}$ and were significantly less than after the $20 \mathrm{~g}$ dose of lactulose $(181.3 \pm 23.9$ $\mu \mathrm{mol} / \mathrm{liter}$, but the area under the curve was similar to that with the $20 \mathrm{~g}$ dose of lactulose (Fig. 4). Breath hydrogen (Fig. $5 B$ ) followed a similar pattern to blood acetate, starting to rise after $6 \mathrm{~h}$ and peaking at $15 \mathrm{~h}(\sim 11 \mathrm{p} . \mathrm{m}$.). Basal levels were reached by $24 \mathrm{~h}$.

Urine was collected throughout the 24-h period. It was noted in every subject that despite a constant diet and fluid intake, urine volumes significantly increased with the pectin dose from $1713 \pm 175$ (control) to $2278 \pm 207 \mathrm{ml}$ (plus pectin) $(t=4.7658, P<0.01)$. 24-h urine acetate excretions were very low at $56.1 \pm 3.5 \mu \mathrm{mol}$ (control) but increased slightly with pectin to $86.8 \pm 13.1 \mu \mathrm{mol}(t=3.0015, P<0.05)$.

\section{Discussion}

The measurement of short chain or volatile fatty acids in biological materials has never been easy as the many papers

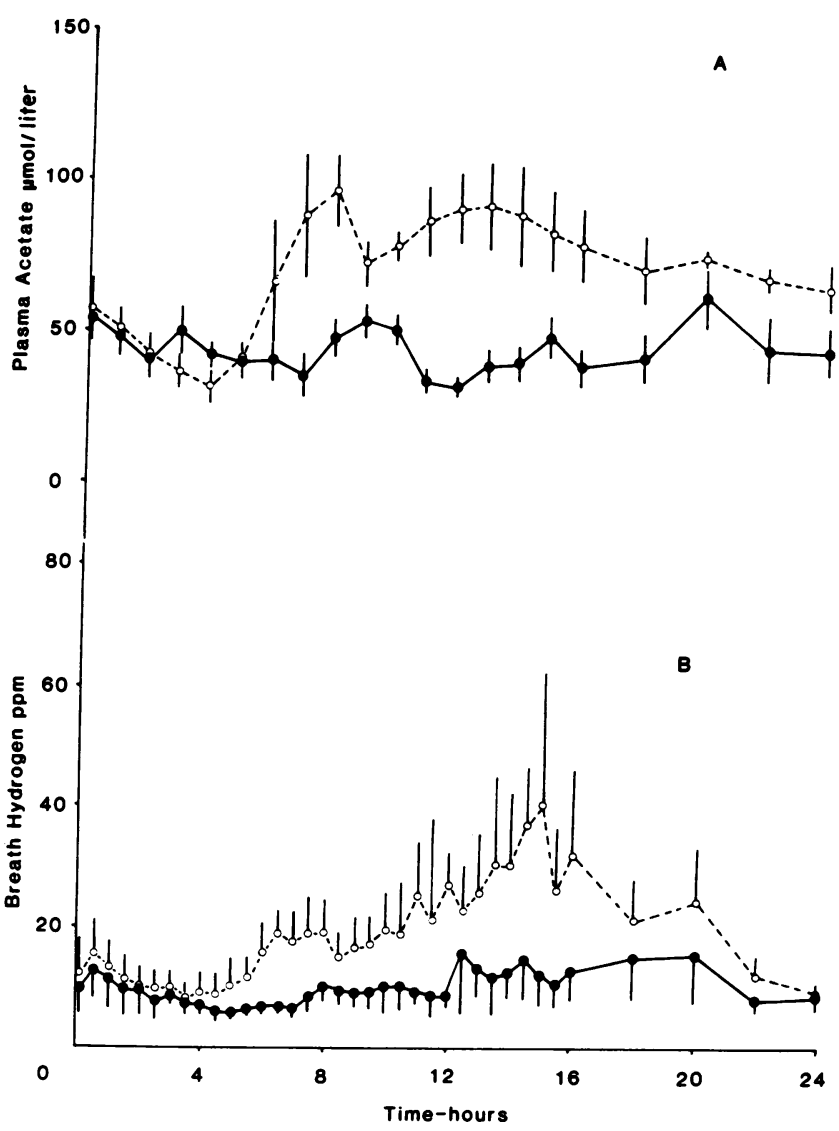

Figure 5. Plasma acetate $(A)$ and breath hydrogen $(B)$ in five subjects while eating a polysaccharide-free diet $(-\bullet-)$ or the same diet to which $20 \mathrm{~g}$ of pectin had been added at time zero (8 a.m.) (-o-). Mean \pm 1 SEM.

describing different techniques testify (23-32). Problems are magnified with human plasma because the levels are 100 to 1000 times lower than in ruminal or colonic contents. We chose to use the vacuum distillation technique $(23,24)$ coupled to the GC method of Illman et al. (25). Vacuum transfer of SCFA avoids steam distillation which can lead to decomposition of acetyl groups from other plasma components and thus falsely high acetate values (26). Solvent extraction after deproteinization, an alternative procedure, is also less than ideal because high concentrations of mineral salts are used, which makes further handling of the sample more difficult and leaves a complex mixture of organic substances to prepare for chromatography (27). Vacuum transfer has the added advantage that it concentrates the sample and thus reduces the volumes of blood required. Initially, as an internal standard, we used isobutyric acid (27), but found that its concentration fell off rapidly on standing in orthophosphoric acid solution, due probably to micellar separation $(27,32)$. The phenomenon was less of a problem with propionate which Tollinger et al. used (30). Care must still be taken, however, to minimize the time between dissolving the residue from the freeze transfer and injection onto the column. Propionic acid, however, is suitable only for human peripheral arterial and venous blood because propionate levels are insignificant ( $<2 \mu \mathrm{mol} / \mathrm{liter})$. In blood where all three SCFA are present, such as portal blood, isobutyrate is preferable. Like Illman et al. (25), we avoided the use of formic acid in the procedure since we found all 
supplies to be unacceptably contaminated with acetic acid. Small amounts of acetate were also found in the phosphoric acid used to make up the standards but this was allowed for in the calculations. Methodological problems which relate to the storage of plasma samples before SCFA assay $(30,32)$ were avoided by commencing the procedure immediately after blood had been obtained from the subject.

Using this technique acetate was found in the fasting blood of all subjects at an average concentration of $53.8 \pm 4.4 \mu \mathrm{mol} /$ liter. These values are similar to those obtained by Tollinger et al. (30) in 27 fasting subjects ( $51 \mu \mathrm{mol} / \mathrm{liter})$ using a similar method but higher than those of Dankert et al. (33) (30.4 $\mu \mathrm{mol} / \mathrm{liter})$ who used vacuum distillation but started with serum rather than plasma from their 10 volunteers. Other reports of fasting levels vary from 100 to $\sim 1000 \mu \mathrm{mol} / \mathrm{liter}$ $(32,34)$. Tangerman et al. (32) used vacuum distillation but also formic acid. Other workers have not used the vacuum transfer technique.

Acetate production during fasting could be from a number of sources both endogenous (liver and peripheral tissues) and exogenous (gut) $(21,35-39)$. In normal fasting animals, for instance, circulating blood acetate is mainly endogenous (liver) in origin in contrast to the fed state, as in the present study, where the gut is the major source $(38,39)$. Human studies of acetate metabolism during fasting are few $(40,41)$. However, following ethanol ingestion $(42,43)$ and in diabetes (44), endogenous production is significant. Plasma acetate concentration and turnover in obese subjects after 1- or 2-wk fasting too may be increased as a result of the conversion of free fatty acids to acetate $(40,41)$.

No significant propionate, butyrate, isobutyrate, valerate, isovalerate, or hexanoate was detected in venous blood in these subjects either during fasting or after the stimulation of fermentation. Acetate, propionate, and butyrate are all produced during fermentation in the human colon (45) but butyrate is metabolized by both rumen $(21,46)$ and colonic epithelium $(7,47,48)$. In man, the molar ratio of acetate to butyrate is much higher in portal blood than in colonic contents (33). The majority of both propionate and butyrate in portal blood is cleared by the liver in both the ruminant (21) and rat (49). The combined effect of colonic mucosal metabolism and hepatic uptake from portal blood serves, therefore, to clear all the propionate and butyrate absorbed from the hind gut and this would appear to be the case in man. Acetate is utilized by peripheral tissues in various mammals (37), including man (40-43), and in our studies, there was evidence for this in the significant fall in acetate concentration between arterial and venous blood in fasting subjects.

Since it was possible that SCFA absorbed from the human gut might be completely cleared from portal blood, it was decided initially in the present study to give a single dose of the three major SCFA by mouth, in the molar proportions found in the colon of man (45), and observe their appearance. As Fig. 1 shows, acetate appeared promptly in blood after an oral dose and was cleared within $1 \mathrm{~h}$ in most cases. The rapid appearance within $15 \mathrm{~min}$ of the dose suggests that the acids were absorbed from the stomach. At the $\mathrm{pH}$ of the fasting stomach ( $\mathrm{pH} \mathrm{1.5-2.0),} \mathrm{these} \mathrm{acids} \mathrm{(} \mathrm{pKa} \mathrm{4.8)}$ would be protonated, a form in which they are thought to cross the gut epithelium readily $(19,50-52)$.

Lactulose is a disaccharide of galactose and fructose $(0-\beta$ D-galactopyranosyl-1-4-D-fructofuranose) and has been used extensively in studies of gut function in man. It largely escapes digestion in the small intestine but is broken down in the colon (53), unless doses well in excess of $20 \mathrm{~g}$ are given. In the present study, no subjects experienced any untoward symptoms after taking lactulose but most noticed a temporary increase in flatus production. Ingestion of lactulose led to a rise in blood acetate in all subjects at all doses. The onset of the rise was considerably delayed with the $5 \mathrm{~g}$ dose $(171 \pm 41$ $\mathrm{min}$ ) but less so with the larger doses. This dose-related delay, which has also been observed in studies of breath hydrogen production $(54,55)$, is a function of the rate of passage of lactulose through the small bowel, and in turn, can be explained by the differing osmolar loads of the various doses. In contrast to the rapid clearance of SCFA taken orally, blood acetate levels were high for 4-5 $\mathrm{h}$ after the first rise following lactulose in most subjects. This prolonged rise probably reflects the time scale of the fermentative process and the fact that lactulose is delivered to the cecum from the small bowel over a period of time rather than as a single bolus as a result of gastric emptying and passage through the small bowel. There was no suggestion from these studies that fermentation proceeded any differently after the second and third dose which the subjects received.

Pectin is broken down in the human gut (56), almost certainly in the large intestine (57). The rate at which it travels through the stomach and small bowel and is fermented in the colon is, however, slower than for a similar amount of lactulose. This slower transit time was reflected in the 6-h delay between the breakfast dose and the rise in either blood acetate concentrations or breath hydrogen. Levels then remained elevated for a further $12 \mathrm{~h}$. Fermentation of polysaccharides in wholewheat bread is also prolonged for many hours (58) so that a subject eating regularly will probably have blood acetate levels constantly raised above basal values. The peak acetate concentration after pectin was only half that seen after a similar amount of lactulose but the area under the curve was not significantly different for the two substances (Fig. 4). The clear difference, however, in blood acetate levels after lactulose and pectin shows that the physical properties of carbohydrate may be important in determining the rate of SCFA production and absorption in the colon. The total amounts of SCFA produced during fermentation cannot be assessed from these experiments but the areas under the curve for the acetate allow comparisons to be made between carbohydrates in a similar way to those which have been made using breath hydrogen (59).

The results of these studies are consistent with the view that SCFA are absorbed from the gut but that propionate and butyrate are cleared by the colonic mucosa and liver. Acetate reaches peripheral tissues where it is metabolized. Venous blood acetate in the nonfasting state can be quantitatively related to carbohydrate breakdown in the colon although concentrations vary with different substrates. Breath hydrogen and blood acetate are related but not breath methane.

\section{Acknowledgments}

The authors wish to express their thanks to Hans Englyst for dietary polysaccharide analysis, to Dr. Marinos Elia for arterial and venous blood samples, to Dr. Sheila Bingham for help with the planning and delivery of the diets, to Stephen Best for assistance with the studies, and to the volunteers for their patience and forbearance.

Dr. Pomare acknowledges gratefully the University of Otago, the Royal Australasian College of Physicians, and the Todd Foundation for their support. 


\section{References}

1. Blaxter, K. L. 1962. The Energy Metabolism of Ruminants. Hutchinson Books Ltd., London. 329 pp.

2. Hungate, R. E. 1966. The Rumen and Its Microbes. Academic Press, New York. 533 pp.

3. Argenzio, R. A., M. Southworth, and C. E. Stevens. 1974. Sites of organic acid production and absorption in the equine gastrointestinal tract. Am. J. Physiol. 226:1043-1050.

4. Argenzio, R. A., and M. Southworth. 1974. Sites of organic acid production and absorption in gastrointestinal tract of the pig. Am. $J$. Physiol. 228:454-460.

5. Henning, S. J., and F. J. R. Hird. 1970. Concentration and metabolism of volatile fatty acids in the fermentative organs of 2 species of kangaroo and the guinea-pig. Br. J. Nutr. 24:145-155.

6. Rechkemmer, G., and W. Von Engelhardt. 1981. Absorptive processes in different colonic segments of the guinea-pig and the effects of short chain fatty acids. In Colon and Nutrition. H. Kasper and $\mathrm{H}$. Goebell, editors. Falk Symp. 32:61-67.

7. Remesy, C., and C. Demigne. 1976. Partition and absorption of volatile fatty acids in the alimentary canal of the rat. Ann. Rech. Vet. 7:39-55.

8. Argenzio, R. A. 1982. Volatile fatty acid production and absorption from the large intestine of the pig. In Physiologie Digestive chez le Porc. J. P. Laplace, T. Corring, and A. Rerat, editors. 2e Seminaire International. Institut National de la Recherche Agronomique, Paris. 207-215.

9. Hoover, W. H., and R. N. Heitmann. 1972. Effects of dietary fiber levels on weight gain, cecal volume and volatile fatty acid production in rabbits. $J$. Nutr. 102:375-380.

10. Imoto, S., and S. Namioka. 1983. Nutritive value of acetate in growing pigs. J. Anim. Sci. 56:858-866.

11. Cummings, J. H. 1983. Fermentation in the human large intestine: evidence and implications for health. Lancet. I:1206-1209.

12. Wrong, O., A. Metcalfe-Gibson, R. B. I. Morrison, S. T. Ng, and A. V. Howard. 1965. In vivo dialysis of faeces as a method of stool analysis. I. Technique and results in normal subjects. Clin. Sci. 28:357-375.

13. Levitt, M. D. 1969. Production and excretion of hydrogen gas in man. N. Engl. J. Med. 281:122-127.

14. Bond, J. H., R. R. Engel, and M. D. Levitt. 1971. Factors influencing pulmonary methane excretion in man. J. Exp. Med. 133: 572-588.

15. Bond, J. H., Jr., and M. D. Levitt. 1976. Fate of soluble carbohydrate in the colon of rats and man. J. Clin. Invest. 57:11581164.

16. Owens, F. N., and H. R. Isaacson. 1977. Ruminal microbia yields: factors influencing synthesis and bypass. Fed. Proc. 36:198202.

17. Harrison, D. G., and A. B. McAllen. 1980. Factors affecting microbial growth yields in the reticulo-rumen. In Digestive Physiology and Metabolism in Ruminants. Y. Ruckebusch and P. Thivend, editors. MTP Press Ltd., Lancaster. 205-226.

18. McNeil, N. I., J. H. Cummings, and W. P. T. James. 1978. Short chain fatty acid absorption by the human large intestine. Gut. 19:819-822.

19. Ruppin, H., S. Bar-Meir, K. H. Soergel, C. M. Wood, and M. G. Schmitt. 1980. Absorption of short chain fatty acids by the colon. Gastroenterology. 78:1500-1507.

20. Bergman, E. N., and J. E. Wolff. 1971. Metabolism of volatile fatty acids by liver and portal-drained viscera in sheep. Am. J. Physiol. 221:586-592.

21. Bergman, E. N. 1975. Production and utilization of metabolites by the alimentary tract as measured in portal and hepatic blood. In Digestion and Metabolism in the Ruminant. I. W. McDonald and A. C. I. Warner, editors. Proceedings of the IV International Symposium on Ruminant Physiology, Sydney, Australia. University of New England Publishing Unit. 292-305.
22. Roediger, W. E. W. 1980. Role of anaerobic bacteria in the metabolic welfare of the colonic mucosa in man. Gut. 21:793-798.

23. Vreman, H. J., J. A. Dowling, R. A. Raubach, and M. W. Weiner. 1978. Determination of acetate in biological material by vacuum distillation and gas chromatography. Anal. Chem. 50:11381141.

24. Tyler, J. E., and G. H. Dibdin. 1975. Gas chromatography of volatile fatty acids: method involving separation from biological material by vacuum distillation. J. Chromatogr. 105:71-77.

25. Illman, R. J., R. P. Trimble, A. M. Snoswell, and D. L. Topping. 1982. Daily variations in the concentrations of volatile fatty acids in the splanchnic blood vessels of rats fed diets high in pectin and bran. Nutr. Rep. Int. 26:439-446.

26. Kurtz, D. J., H. L. Levy, W. Plotkin, and Y. Kishimoto. 1971. A rapid method for the quantitative analysis of short-chain fatty acids in serum or plasma. Clin. Chim. Acta. 34:463-466.

27. Remesy, C., and C. Demigne. 1974. Determination of volatile fatty acids in plasma after ethanolic extraction. Biochem. J. 141:8591.

28. Cochrane, G. C. 1975. A review of the analysis of the free fatty acids $\mathrm{C}_{2}-\mathrm{C}_{6}$. J. Chromatogr. Sci. 13:440-447.

29. Whitehead, J. S., Y. S. Kim, and R. Prizont. 1976. A simple quantitative method to determine short-chain fatty acid levels in biological fluids. Clin. Chim. Acta. 72:315-318.

30. Tollinger, C. D., H. J. Vreman, and M. W. Weiner. 1979. Measurement of acetate in human blood by gas chromatography: effects of sample preparation, feeding and various diseases. Clin. Chem. 25:1787-1790.

31. McArthur, B., and A. P. Sarnaik. 1982. Quantification of shortchain fatty acids in plasma. Clin. Chem. 28:1983-1984.

32. Tangerman, A., A. van Schaik, M. T. Neuwese-Arends, and J. H. M. van Tongeren. 1983. Quantitative determination of $C_{2}-C_{8}$ volatile fatty acids in human serum by vacuum distillation and gas chromatography. Clin. Chim. Acta. 133:341-348.

33. Dankert, J., J. B. Zijlstra, and B. G. Wolthers. 1981. Volatile fatty acids in human peripheral and portal blood: quantitative determination by vacuum distillation and gas chromatography. Clin. Chim. Acta. 110:301-307.

34. Lai, J. C. K., D. B. A. Silk, and R. Williams. 1977. Plasma short-chain fatty acids in fulminant hepatic failure. Clin. Chim. Acta. 78:305-310.

35. Annison, E. F., and R. R. White. 1962. Further studies on the entry rates of acetate and glucose in sheep, with special reference to endogenous production of acetate. Biochem. J. 84:546-552.

36. Ballard, F. J. 1972. Supply and utilization of acetate in mammals. Am. J. Clin. Nutr. 25:773-779.

37. Knowles, S. E., I. G. Jarrett, O. H. Filsell, and F. J. Ballard. 1974. Production and utilization of acetate in mammals. Biochem. $J$ 142:401-411.

38. Buckley, B. M., and D. H. Williamson. 1977. Origins of blood acetate in the rat. Biochem. J. 166:539-545.

39. Pethick, D. W., D. B. Lindsay, P. J. Barker, and A. J. Northrop. 1981. Acetate supply and utilization by the tissues of sheep in vivo. Br. J. Nutr. 46:97-1 10.

40. Skutches, C. L., C. P. Holroyde, R. N. Myers, and G. A. Reichard. 1979. Plasma acetate turnover and oxidation. J. Clin. Invest. 64:708-713.

41. Seufert, C. D., W. Mewes, and H. D. Soeling. 1984. Effect of long-term starvation on acetate and ketone body metabolism in obese patients. Europ. J. Clin. Invest. 14:163-170.

42. Lindeneg, O., K. Mellemgaard, J. Fabricius, and F. Lundquist. 1964. Myocardial utilization of acetate, lactate and free fatty acids after ingestion of ethanol. Clin. Sci. 27:427-435.

43. Lundquist, F., L. Sestoft, S. E. Damgaard, J. P. Clausen, and J. Trap-Jensen. 1973. Utilization of acetate in the human forearm during exercise after ethanol ingestion. J. Clin. Invest. 52:3231-3235.

44. Seufert, C. D., W. Mewes, G. Dietrich, R. Durigen, G. Janson, A. Kuhn, P. Grigat, and H. D. Soling. 1974. Formation of free acetate 
and ketone bodies in the normal, starved and diabetic state. Diabetologia 10:386-391.

45. Cummings, J. H. 1981. Short chain fatty acids in the human colon. Gut. 22:763-779.

46. Stevens, C. E., and B. K. Stettler. 1966. Transport of fatty acid mixtures across rumen epithelium. Am. J. Physiol. 211:264-271.

47. Roediger, W. E. W. 1980. The colonic epithelium in ulcerative colitis: an energy-deficient disease? Lancet. II:712-715.

48. Roediger, W. E. W. 1982. Utilization of nutrients by isolated epithelial cells of the rat colon. Gastroenterology. 83:424-429.

49. Remesy, C., C. Demigne, and F. Chartier. 1980. Origin and utilization of volatile fatty acids in the rat. Reprod. Nutr. Develop. 20: 1339-1349.

50. Sallee, V. L., and J. M. Dietschy. 1973. Determinants of intestinal mucosal uptake of short- and medium-chain fatty acids and alcohols. J. Lipid Res. 14:475-484.

51. Argenzio, R. A., and S. C. Whipp. 1979. Inter-relationship of sodium, chloride, bicarbonate and acetate transport by the colon of the pig. J. Physiol. 295:365-381.

52. Stevens, C. E. 1970. Fatty acid transport through the rumen epithelium. In Physiology of Digestion and Metabolism in the Ruminant. A. T. Phillipson, editor. Oriel, Newcastle-on-Tyne. 101-112.

53. Saunders, D. R., and H. S. Wiggins. 1981. Conservation of mannitol, lactulose, and raffinose by the human colon. Am. J. Physiol. 241:G397-G402.
54. Bond, J. H., and M. D. Levitt. 1975. Investigation of small bowel transit time in man utilising pulmonary hydrogen $\left(\mathrm{H}_{2}\right)$ measurements. J. Lab. Clin. Med. 85:546-555.

55. La Brooy, S. J., P.-J. Male, A. K. Beavis, and J. J. Misiewicz. 1983. Assessment of the reproducibility of the lactulose $\mathrm{H}_{2}$ breath test as a measure of mouth to caecum transit time. Gut. 24:893-896.

56. Cummings, J. H., D. A. T. Southgate, W. J. Branch, H. S Wiggins, H. Houston, D. J. A. Jenkins, T. Jivraj, and M. H. Hill. 1979. The digestion of pectin in the human gut and its effect on calcium absorption and large bowel function. Br. J. Nutr. 41:477-485.

57. Sandberg, A.-S., R. Ahderinne, H. Andersson, B. Hallgren, and L. Hulten. 1983. The effect of citrus pectin on the absorption of nutrients in the small intestine. Human Nutr. Clin. Nutr. 37C:171183.

58. Jenkins, D. J. A., M. J. Thorne, K. Camelon, A. Jenkins, A. Venketeshwer Rao, R. H. Taylor, L. U. Thompson, J. Kalmusky, R. Reichert, and T. Francis. 1982. Effect of processing on digestibility and the blood glucose response: a study of lentils. Am. J. Clin. Nutr. 36:1093-1101.

59. Anderson, I. H., A. S. Levine, and M. D. Levitt. 1981. Incomplete absorption of the carbohydrate in all-purpose wheat flour. N. Engl. J. Med. 304:891-892.

60. Prins, R. A. 1977. Biochemical activities of gut micro-organisms. In Microbiol Ecology of the Gut. R. F. J. Clarke and T. Bauchop, editors. Academic Press, London. 73-183. 